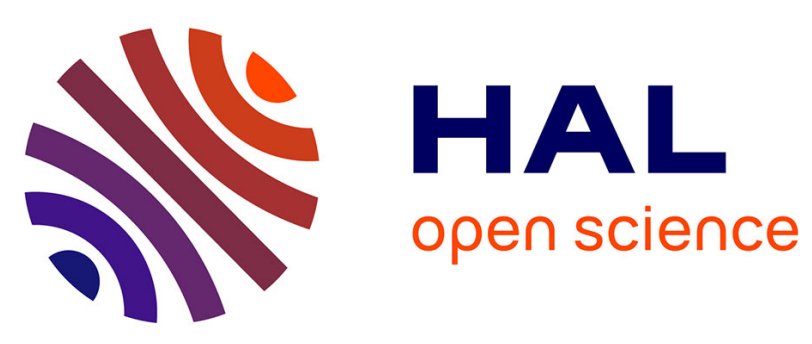

\title{
Using an Ultrasonic Transducer to Produce Tactile Rendering on a Touchscreen
}

\author{
Frédéric Giraud, Christophe Giraud-Audine, Michel Amberg, Betty \\ Lemaire-Semail
}

\section{- To cite this version:}

Frédéric Giraud, Christophe Giraud-Audine, Michel Amberg, Betty Lemaire-Semail. Using an Ultrasonic Transducer to Produce Tactile Rendering on a Touchscreen. Joint IEEE International Symposium on the Applications of Ferroelectrics, International Workshop on Acoustic Transduction Materials and Devices \& Workshop on Piezoresponse Force Microscopy (ISAF/IWATMD/PFM), May 2014, PENN STATE, United States. 10.1109/ISAF.2014.6922972 . hal-01018415

\section{HAL Id: hal-01018415 https://hal.science/hal-01018415}

Submitted on 12 Aug 2014

HAL is a multi-disciplinary open access archive for the deposit and dissemination of scientific research documents, whether they are published or not. The documents may come from teaching and research institutions in France or abroad, or from public or private research centers.
L'archive ouverte pluridisciplinaire HAL, est destinée au dépôt et à la diffusion de documents scientifiques de niveau recherche, publiés ou non, émanant des établissements d'enseignement et de recherche français ou étrangers, des laboratoires publics ou privés. 


\title{
Using an Ultrasonic Transducer to Produce Tactile Rendering on a Touchscreen
}

\author{
Frédéric Giraud ${ }^{1}$, Christophe Giraud-Audine ${ }^{2}$, Michel Amberg ${ }^{1}$, Betty Lemaire-Semail ${ }^{1}$ \\ 1 Laboratory of Electrical Engineering and Power Electronic, \\ University Lille1 \\ 59000 Villeneuve d'Ascq, France \\ name.surname@univ-lille1.fr \\ 2 Laboratory of Electrical Engineering and Power Electronic, \\ Arts\&Métiers Paris Tech \\ 59000 Lille, France \\ christophe.giraud-audine@ensam.eu
}

\begin{abstract}
Friction reduction based tactile devices use an ultrasonic vibration to create an overpressure between a user's fingertip and the vibrating surface. This phenomenon is called "the squeeze film effect". This is an emerging technology to produce a haptic feedback on the touchscreen of handheld electronic devices. In this paper, we present the technology and the main technological issues to be improved.
\end{abstract}

Tactile, Haptic, squeeze film, piezoelectric.

\section{INTRODUCTION}

Our everyday Life is now rich of electronic and portable devices which interact with a user through a touch screen. These type of interfaces are now a standard for mobile phones or tablets, and they replace physical buttons or knobs in Computer to Human Interfaces. However, they no longer receive any affordance cues - the click of a keyboard button for example. To cope with this problem, some touch screens now embed actuators which provide haptic feedback creating vibro-tactile sensations.

The limited bandwidth of vibro-tactile actuators, and the fact that the sensation is produced all over the portable device and not only at the fingerpulp in contact with the touch screen make a realistic simulation of touching programmable surfaces difficult. Hence, vibro-tactile actuators are used to give an information through the sense of touch [1] or improve the user's experience when watching a video for example [2]. With vibro-tactile actuators, the user's hand is fixed onto the device, and passively obtain tactile stimulation.

On the contrary, friction reduction based tactile devices modify the friction coefficient, and thus require the motion of the finger to activate the tactile effect. In addition with a position sensor, which locates the user's fingertip onto the active area, the stimulation is a function of finger's position and several effect can be programmed like touching gratings [3], fabrics [4] or feeling the icons on the desktop environment [5]. In [6], the authors first introduced the squeeze film effect in a tactile applications. And other papers described many realizations. For example, [7] uses surface acoustic waves, and [8] uses travelling waves.
To be implemented in consumer electronic device, the implementation of the friction reduction has to be compliant with the existing touch screens, among other things (like the cost). This is why, the paper is focused on the technological aspects of the implementation of the squeeze film in a tactile display. First, we describe the squeeze film effect, and the implied requirements. Then we discuss some technological issues, to finally conclude with a presentation of some users experiences.

\section{PRINCIPLE}

\section{A. The Squeeze Film Effect}

When studying the squeeze film effect, we consider two plates, one vibrating opposite to an other one. The air trapped into the air gap expands and contracts due to the vibration, and the pressure decreases (expansion) and increases (contraction) as a function of time. If this transformation is isothermal, it is also a non-linear transformation. This results in an overpressure, named "the squeeze film", which can be used to lift up object, to create damping in Micro Electro Mechanical Systems (MEMS), or to create active lubrication [9]. In [10], the authors have calculated the expected overpressure in the case of a $1 \mathrm{~mm}^{2}$ square surface. They emphasize the border effect: at the edges of the surface, the overpressure is equal to zero, an linearly increase up to the maximal overpressure. hence, to be efficient, the border effect should be neglected. For that purpose, the squeeze number $\sigma$ should be well above 10. The squeeze number is defined as follows[9]:

$$
\sigma=\frac{24 \pi \eta f_{0} l_{0}}{p_{0} h_{0}}
$$

with $\eta$ the viscosity of air, $f_{0}$ the working frequency, $l_{0}$ the average length of the contact surface, $p_{0}$ the surrounding pressure and $h_{0}$ the surface roughness.

The squeeze number depends on the vibrations frequency $f_{0}$, all the other parameters being fixed. The resulting condition is $f_{0}>25 \mathrm{kHz}$ to avoid the border effect. For example, in [10], the authors have calculated that the maximal overpressure is obtained $1 \mathrm{~mm}$ apart of the plate's edges with $\sigma=20$.

This work has been carried out within the framework of the Mint project of Inria (France) and the StimTac Project of the Institut de Recherche sur les Composantans logIciels et matériels pour la Communication Avancée (IRCICA) 


\section{B. Vibration amplitude}

In [11], the overpressure $P_{\infty}$ produced by the squeeze film effect, is calculated, taking into account the effect of the epidermal ridges of the finger pulp. Then, the friction reduction is calculated using:

$$
\mu=\mu_{0}\left(1-\frac{P_{\infty}}{P_{T}}\right)
$$

with $\mu_{0}$ is the initial friction coefficient of the finger on the surface, $P_{T}$ is the initial contact pressure, typically $1 \mathrm{~N} / \mathrm{cm}^{2}$.

Actual measurements on a prototype are presented in figure 1 . They show that to obtain a friction reduction of $50 \%$, which is detectable by the users, a vibration amplitude of $1 \mu \mathrm{m}$ is sufficient.

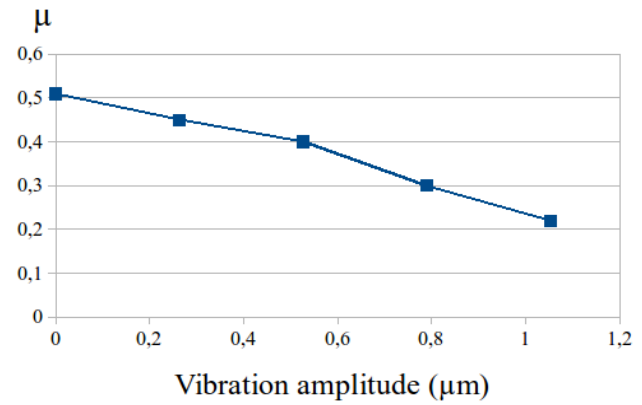

Figure 1. Friction coefficient as a function of the vibration amplitude; experimental measurements on a prototype

Hence, a vibration of a plate at $25 \mathrm{kHz}$ and above, with an amplitude of $1 \mu \mathrm{m}$ and above can produce a friction reduction which is felt by the user. This gives rise to the minimal requirements of a tactile plate using the squeeze film effect.

This vibration is not directly felt by the mechano receptors of the skin, because it is well above their bandwidth. It is the effect of the vibration which is actually felt. The squeeze film is able to change a high friction surface into a low friction surface, as if it was lubricated. Yet more sophisticated surfaces can be simulated, by modulating the friction as a function of the position. The example of gratings is detailed in the next section.

\section{Modulation of the friction}

When modulating the vibration amplitude, the lateral forces are modified, and this can be done dynamically, by modulating the voltage across the piezoelectric material. This change in the lateral force can be interpreted as a bump or a hole. To achieve this tactile illusion, the position of the fingertip is measured, and an algorithm compute the required vibrtation amplitude. For example, the bump of the figure 2 can be simulated with a zone of high friction $(W=0)$ surrounded by a zone of low friction $(W>1 \mu m)$. The resulting algorithm is given by :

$$
\begin{aligned}
& \text { if }(|x f|>X b)\{ \\
& \text { \}else } \\
& \left\{\begin{array}{l}
W=W \max ; \\
\}
\end{array} \quad W=0 ;\right.
\end{aligned}
$$

wher $\mathrm{X}_{\mathrm{f}}$ is the position of the fingertip, $2 \mathrm{X}_{\mathrm{B}}$ is the length of the bump and Wmax is the maximal vibration amplitude.

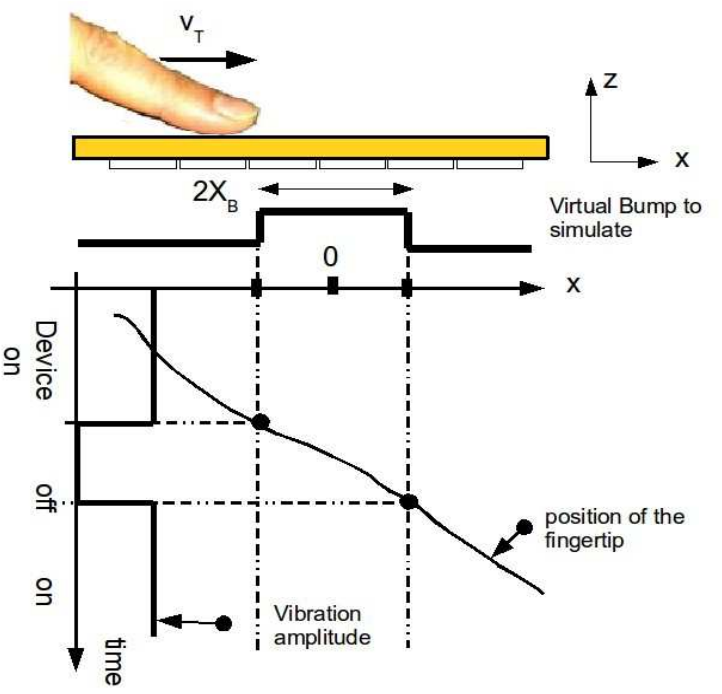

Figure 2. A virtual bump simulated using the friction modulation

To implement this principle in a haptic display, several technological issues have to face of. The next section presents some of them, with devised solutions.

\section{TECHNOLOGICAL ISSUES}

When designing a tactile display based on friction reduction, size matters. Indeed, the tactile feedback is obtained with a movement of the fingertip on the active surface. The user needs to have free movements to explore the tactile rendering of the proposed surface. Moreover, the power consumption is critical, since the tactile feedback should be available on portable devices, which often run on batteries. Also, the display should be transparent, and compatible with the capacitive technology of the touch screens. Finally, the vibration amplitude has to be dynamically controlled in order to obtain better stimulation. These issues are adressed in the following sections of this paper.

\section{A. Enlarging the active area}

First attempts to create a tactile display with the squeeze film could use a $25 \mathrm{~mm}$ disk as in [12]. The authors used the first bending mode of the disk. The area is too small and roughly allows the movement of the fingertip. To enlarge the active area, one could increase the diameter of the disk. However, since the eigen frequency of the 1st bending mode decreases as the disk's diameter increases, large diameter implies low frequency, and the condition $f_{0}>25 \mathrm{kHz}$ can no longer be fulfilled.

This is why, we have proposed to use several wavelength $\lambda$ over the touched surface. Figure 3 shows StimTac as we call our prototype. It is built up with a plate of copper, on which 28 piezoelectric elements are bonded. 


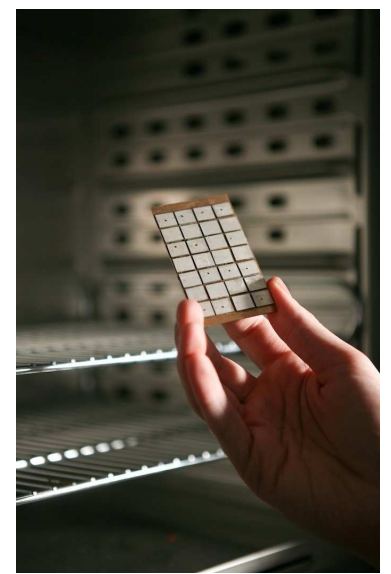

Figure 3. Manufacturing StimTac, the prototype

The resulting mode shape is presented in Fig. 4. It shows 7 antinodes of vibration, there are 4.5 wavelengths over the active area.

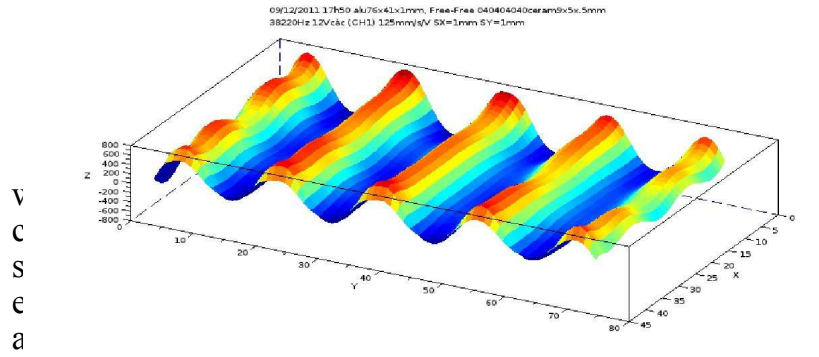

However, producing the squeeze film with several wavelength is not ideal. Indeed, more friction reduction is obtained at the antinodes of vibration compared to the nodes, and the rendering is not homogenous over the active area, as depicted in figure 5 .

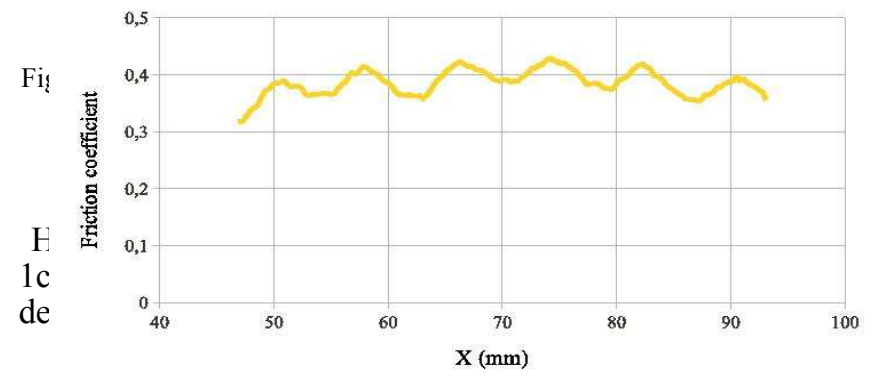

B. I vwer cornsurnpıun

The power supplied to the vibrating plate is shared into power losses in the resonator, and the power absorbed by the finger in contact. However, from our point of view, the absorption by the finger is negligible, and we can consider that almost all the power is transformed into heat.

Our first designs needed more than $5 \mathrm{~W}$ to vibrate at $1 \mu \mathrm{m}$. This increased the temperature of the plate, and was not an acceptable level of power consumption, as it is for example more than the available power from a USB port.

We conducted a study [13], and proposed several designs. With the optimal design, we needed less than $250 \mathrm{~mW}$. To achieve this result, we reduced the thickness of the plate, from
$2 \mathrm{~mm}$ to $0.7 \mathrm{~mm}$. Lower thickness cannot be used, as it makes the resonator more brittle.

\section{Transparent tactile displays}

To be transparent, the resonator should be made of a transparent material, like glass since it is easily available, and be free of the piezoelectric elements. In [14], the authors have glued one piezoelectric cell placed in a corner of the glass plate. However, in commercial use, this part of the plate should be hidden with a mask, thus reducing the active area.

We have proposed to use exciters instead [15]. Exciters are built up with two plates of copper on which the piezoelectric elements are bonded. The exciters are then glued at the edges of the glass plate, as shown in figure 6. By this way, the active area is totally free of non-transparent material, yet allowing a good homogeneity of the friction reduction.

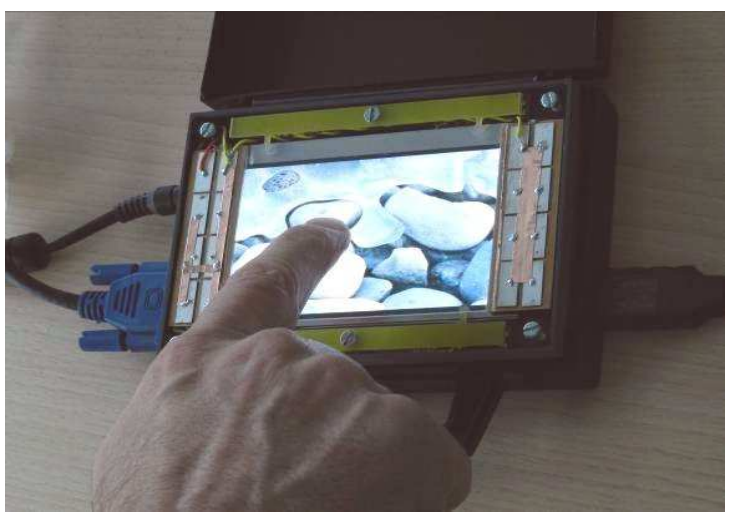

Figure 6. The transparent prototype with its exciters

\section{Control of the stimulation}

When pressing the fingertip on the resonator, the mechanical coupling changes the resonant behavior of the plate. The resonant frequency changes, and an additional damping occurs. If no action is taken, the vibration amplitude can be changed, depending whether the user touches the tactile stimulator or not, and which force is applied by the user. This behavior is depicted in figure 7, where we show the vibration amplitude $W$ as a function of time, and the force $F_{N}$.
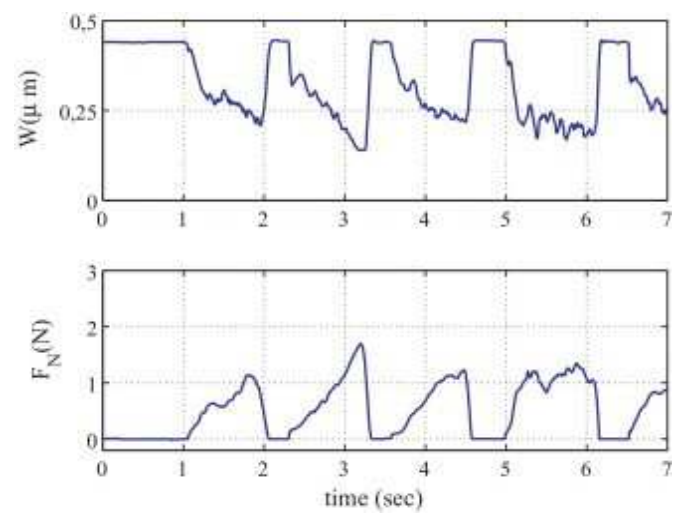

Figure 7. Vibration amplitude as a function of time, for a constant reference and different normal force exerted by the user. 
A closed loop control is thus necessary. This is why, an additional piezoelectric element is used as a vibration sensor [16].

\section{CONCLUSION}

This paper presents the friction reduction based tactile devices which use the squeeze film effect to produce a modification of the perception a user has of a surface. They require ultrasonic vibrations at low amplitude.

Then, some technological issues are discussed. A survey of our proposed methods to cope with these problems are presented. The implementation of the squeeze film effect reveals to be compatible with touch screens of some consumer electronics.

\section{REFERENCES}

[1] E. Hoggan, S. A. Brewster, et J. Johnston, « Investigating the Effectiveness of Tactile Feedback for Mobile Touchscreens », in Proceedings of the SIGCHI Conference on Human Factors in Computing Systems, New York, NY, USA, 2008, p. 1573-1582.

[2] M. Y. Sung, K. Jun, D. Ji, H. Lee, et K. Kim, « Touchable Video and Tactile Audio », in 11th IEEE International Symposium on Multimedia, 2009. ISM '09, 2009, p. 425-431.

[3] M. Biet, G. Casiez, F. Giraud, et B. Lemaire-Semail, « Discrimination of Virtual Square Gratings by Dynamic Touch on Friction Based Tactile Displays », in symposium on Haptic interfaces for virtual environment and teleoperator systems, 2008, 2008, p. 41-48.

[4] M.-A. Bueno, B. Lemaire-Semail, M. Amberg, et F. Giraud, «A simulation from a tactile device to render the touch of textile fabrics: a preliminary study on velvet », Textile Research Journal, p. 1-13, févr. 2014.

[5] G. Casiez, N. Roussel, R. Vanbelleghem, et F. Giraud, « Surfpad: riding towards targets on a squeeze film effect », CHI'11, 2011, p. 2491-2500
[6] T. Watanabe and S. Fukui. A method for controlling tactile sensation of surface roughness using ultrasonic vibration. IEEE Int. Conf. on Robotics and Automation, pages 1134-1139, 1995.

[7] M. Takasaki, Y. Fujii, H. Kotani, T. Mizuno, and T. Nara. Proposal of tele-touch using active type saw tactile display. In IEEE/RSJ International Conference on Intelligent Robots and Systems, pages 1032-1037, October 2006.

[8] X. Dai, J. E. Colgate, et M. A. Peshkin, « LateralPaD: A surface-haptic device that produces lateral forces on a bare finger », in 2012 IEEE Haptics Symposium (HAPTICS), 2012, p. 7-14.

[9] W. E. Langlois, «ISOTHERMAL SQUEEZE FILMS », INTERNATIONAL BUSINESS MACHINES CORP SAN JOSE CA, RJ-192, mai 1961.

[10] C. Winter et Y. Perriard, « Modeling of the air film pressure for a haptic touch actuator ", in Proceedings of the 2011-14th European Conference on Power Electronics and Applications (EPE 2011), 2011, p. 1-8.

[11] M. Biet, F. Giraud, et B. Lemaire-Semail, « Squeeze film effect for the design of an ultrasonic tactile plate », IEEE Transactions on Ultrasonics, Ferroelectrics and Frequency Control, vol. 54, n 12, p. 2678-2688, déc. 2007.

[12] L. Winfield, J. Glassmire, J. E. Colgate, et M. Peshkin, « T-PaD: Tactile Pattern Display through Variable Friction Reduction », in EuroHaptics Conference, 2007 and Symposium on Haptic Interfaces for Virtual Environment and Teleoperator Systems. World Haptics 2007. Second Joint, 2007, p. 421-426.

[13] F. Giraud, M. Amberg, R. Vanbelleghem, et B. Lemaire-Semail, «Power Consumption Reduction of a Controlled Friction Tactile Plate ", in Haptics: Generating and Perceiving Tangible Sensations, vol. 6192, A. M. L. Kappers, J. B. F. Erp, W. M. Bergmann Tiest, et F. C. T. Helm, Éd. Berlin, Heidelberg, 2010, p. 44-49.

[14] N. D. Marchuk, J. E. Colgate, et M. A. Peshkin, «Friction measurements on a Large Area TPaD», in 2010 IEEE Haptics Symposium, 2010, p. 317-320.

[15] F. Giraud, M. Amberg, B. Lemaire-Semail, et G. Casiez, « Design of a transparent tactile stimulator », in 2012 IEEE Haptics Symposium (HAPTICS), 2012, p. 485-489.

[16] F. Giraud, M. Amberg, et B. Lemaire-Semail, « Design and control of a haptic knob », Sensors and Actuators A: Physical, vol. 196, p. 78-85, juill. 2013. 